ojs.unud.ac.id/index.php/mettek

\title{
Desain Mekanisme Ballscrew untuk Retrofit Drilling axis Mesin Ficep H-Beam Drilling LFB-200-49
}

\author{
Kimar Turnip ${ }^{1)^{*}}$, Priyono Atmadi ${ }^{2)}$, Andreas Agung Novianto ${ }^{3)}$ \\ ${ }^{1,2,3)}$ Teknik Mesin Universitas Kristen Indonesia \\ Jl. Mayjen Sutoyo No. 2, Jakarta Timur 13650 \\ Email: kimar.turnip@uki.ac.id; priyono.atmadi@uki.ac.id; agungcc@yahoo.co.id
}

doi: https://doi.org/10.24843/METTEK.2021.v07.i01.p02

\begin{abstract}
Abstrak
Proses retrofit adalah proses penggantian atau penambahan suatu komponen ke mesin dengan tujuan untuk memberikan nilai tambah pada performa mesin tersebut. Pada penelitian ini, proses retrofit diaplikasikan pada penggantian penggerak drilling axis mesin Ficep H-beam Drilling LFB-200-49. Proses retrofit ini membutuhkan komponen motor servo sebagai energi penggerak dan ballscrew sebagai pengubah rotasi motor menjadi gerakan linear twist drill saat melakukan proses pengeboran untuk menggantikan sistem hidrolik yang digunakan sebelumnya. Pada perancangan retrofit yang dilakukan terhadap mesin Ficep $H$-beam Drilling ini, gaya dorong yang dihasilkan sistem hidrolik digunakan sebagai acuan untuk mengetahui kebutuhan dynamic load yang harus ditransmisikan oleh ballscrew sedangkan thrust axial force dari mata bor digunakan sebagai acuan dalam menentukan daya motor servo. Dalam merancang penggantian sistem hidrolik ke sistem motor servo ini, komponen yang disarankan adalah ballscrew dengan pitch $10 \mathrm{~mm}$ dan diameter poros ballscrew 38 $\mathrm{mm}$ yang memenuhi syarat transmisi dynamic load 50.210,56 $\mathrm{N}$ dan motor servo dengan daya $8,12 \mathrm{~kW}$ dengan penambahan gear ratio $3: 1$.
\end{abstract}

Kata kunci: Ballscrew, Hidrolik, Motor Servo, Retrofit

\begin{abstract}
The retrofit process is the process of replacing or adding a component to a machine with the aim of adding value to the machine's performance. In this study, the retrofit process was applied to the replacement of the Ficep H-beam Drilling LFB-200-49 drilling machine axis. This retrofitting process requires a servo motor component as driving energy and a ballscrew to convert the motor rotation into a linear twist drill motion during the drilling process to replace the hydraulic system used previously. In the retrofit design carried out on the Ficep H-beam Drilling machine, the thrust generated by the hydraulic system is used as a reference to determine the dynamic load requirements that must be transmitted by the ballscrew while the thrust axial force from the drill bit is used as a reference in determining the power of the servo motor. In designing the replacement of the hydraulic system to this servo motor system, the recommended components are a ballscrew with a pitch of $10 \mathrm{~mm}$ and a ballscrew shaft diameter of $38 \mathrm{~mm}$ which meets the requirements for dynamic load transmission of 50,210.56 $\mathrm{N}$ and a servo motor with a power of $8.12 \mathrm{~kW}$ with the addition of a gear ratio of $3 .: 1$.
\end{abstract}

Keywords: Ballscrew, Hydraulic, Retrofit, Servo motor

Penulis korespondensi,

Email: agungcc@yahoo.co.id 


\section{PENDAHULUAN}

Penerapan teknologi baru dalam suatu industri sangat dibutuhkan. Selain untuk meremajakan mesin, juga dapat meningkatkan kemampuan mesin dalam proses kerjanya dan diharapkan mampu meningkatkan daya saing suatu perusahaan melalui penerapan teknologi baru tersebut pada mesin yang digunakan [1]. Salah satu cara penerapan kemajuan teknologi pada mesin-mesin produksi adalah melakukan proses retrofit. Retrofit adalah proses penggantian atau penambahan peralatan ke mesin yang ada dengan tujuan untuk meningkatkan efisiensi energi, meningkatkan hasil produksi mesin, menambahkan umur pakai mesin, dan menurunkan emisi. Secara prinsip, proses retrofit merupakan langkah-langkah yang digunakan agar suku cadang baru atau yang diperbarui dapat dipasang menggantikan suku cadang yang lama tanpa mengganggu kinerja mesin dalam proses produksi [2].

Beberapa proses retrofit yang telah diteliti sebelumnya. [3] Melakukan penelitian terkait perancangan ulang sistem hidrolik dengan mengganti pipa saluran oli dengan manifold. Hasilnya, jalur hidrolik yang terdapat dalam sistem menjadi lebih ringkas. Penelitian lain adalah penambahan Variabel Frequency Drive (VFD) pada motor pompa hydraulic power unit untuk mengatur frekuensi motor hidrolik yang menghasilkan efisiensi energi 80,65\% [4]. Keuntungan lain dengan penggunaan VFD ini adalah temperatur kerja turun 65\%, aliran oli turun $91 \%$, noise yang muncul pada sistem turun 5,75\%, dan sistem juga tidak berisik tapi lebih kuat dibanding tanpa menggunakan VFD [5].

Proses retrofit diterapkan oleh Parmar pada mesin bubut dengan melakukan penggantian sistem penggerak dengan ballscrew yang digerakkan motor stepper pada mesin bubut konvensional. Penggantian ini mengurangi waktu produksi 25-30\% dan kepresisian meningkat $0,4-0,1 \mathrm{~mm}$ [6]. Harbintoro melakukan penggantian kontrol motor-generator operated drive menjadi variabel speed DC drive. Hasil dari retrofit penggantian sistem ini, konsumsi daya yang dibutuhkan rata-rata dari ketiga phase turun sebanyak $21,5 \%$ [7].

Penelitian yang sejenis dalam hal merubah sistem hidrolik ke motor servo diantaranya melakukan perancangan terhadap sistem ballscrew dan motor servo untuk retrofit sistem hidrolik pada mesin external grinding. Perancangan dan penggantian sistem ini meningkatkan akurasi dan performa mesin sebaik mesin CNC dengan biaya penggantian yang lebih murah dibandingkan dengan pembelian mesin $\mathrm{CNC}$ baru meskipun tidak dicantumkan peningkatan akurasi dan biaya investasi yang dibutuhkan dalam penelitian tersebut[2].

Proses penggantian sistem hidrolik ke motor servo merupakan penerapan teknologi yang memberikan banyak nilai tambah seperti akurasi, maintenance yang lebih mudah, dan kebaruan teknologi yang digunakan. Namun, proses penggantian ini membutuhkan perancangan yang tepat dan sesuai agar proses substitusinya dapat berfungsi dengan baik. Karenanya, penelitian ini ingin memberikan gambaran bagaimana proses merancang mekanisme penggunaan ballscrew dan motor servo untuk menggantikan sistem hidrolik yang tepat dan sesuai sehingga dapat dijadikan rujukan dalam penerapan proses retrofit serupa pada mesin manufaktur lainnya.

\section{METODE}

\subsection{Pengambilan Data Lapangan}

Data lapangan pertama yang dikumpulkan adalah data ukuran diameter twist drill yang digunakan dalam proses pengerjaan di mesin Ficep, pengukuran pada diameter silinder yang digunakan, diameter dari shaft piston pada silinder tersebut, dan jenis material benda kerja yang dikerjakan pada mesin Ficep untuk mengetahui material factor dan cutting speed untuk proses pengeboran material tersebut.

\subsection{Persamaan}

Beberapa persamaan yang digunakan dalam perancangan sebagai berikut

Menghitung putaran spindle yang dibutuhkan mata bor [8] 
ojs.unud.ac.id/index.php/mettek

$$
\text { Spindle Speed } \quad \text { (n) } \quad=\frac{\mathrm{Vc} \times 1000}{\pi \times \mathrm{D}}
$$

Dalam persamaan diatas, D merupakan diameter mata bor sedangkan Vc merupakan kecepatan potong berdasarkan material benda kerja yang akan diproses permesinan. Selanjutnya menghitung kebutuhan thrust axial force tiap komponen mata bor [8]

$$
\text { Thrust axialforce }(\mathrm{T})=11,4 \times \mathrm{k} \times \mathrm{D} \times(100 \mathrm{x} \mathrm{fn})^{0,85}
$$

Dimana $\mathrm{k}$ adalah material factor benda kerja, dan fn adalah laju pemakanan mata bor. Kemudian untuk mencari kebutuhan daya motor servo digunakan rumus [8]

$$
\text { Motor power calculation }=\frac{1,25 \times \mathrm{D}^{2} \times \mathrm{kxns} \times(0,056+1,5 * \mathrm{fn})}{100.000}
$$

Selanjutnya adalah persamaan-persamaan yang akan digunakan untuk analisa sistem hidrolik sebagai berikut

Menghitung luas area kerja silinder [9]

$$
\text { Forward piston area } \quad \text { (A) }=\frac{\pi \times\left(\mathrm{Ds}^{2}-\mathrm{d}^{2}\right)}{4}
$$

Dimana Ds adalah diameter silinder dan d adalah diameter shaft piston. Luas kerja silinder kemudian digunakan untuk mencari gaya yang dihasilkan sistem hidrolik dengan rumus berikut [10]

$$
\mathrm{P} \quad=\quad \frac{\mathrm{F}}{\mathrm{A}}
$$

Persamaan terakhir yang digunakan dalam proses penghitungan adalah persamaan untuk mengetahui gaya yang dihasilkan motor servo dan ballscrew menggunakan rumus berikut [11]

$$
\text { Output force from servo motor }=\frac{\mathrm{T} \times 2 \times 10^{3} \times \pi}{\mathrm{n}}
$$

Dimana $\mathrm{T}$ adalah torsi yang dihasilkan oleh motor servo dan $\mathrm{n}$ adalah pitch ballscrew. Jika gaya keluaran tersebut masih lebih kecil dibanding dengan gaya dari sistem hidrolik maka penentuan perbandingan gear ratio menggunakan persamaan berikut

$$
\text { Ratio } \quad \text { Gear } \quad \frac{\text { Gaya sistem hidrolik }}{\text { Gaya keluaran terbesar motor servo }}
$$

\subsection{Penghitungan}

\subsubsection{Penghitungan Kebutuhan Daya Motor}

Proses penghitungan ini diawali dengan mencari putaran spindle yang dibutuhkan masing-masing mata bor yang digunakan menggunakan persamaan (1). Kemudian dilanjutkan dengan penghitungan thrust axial force masing-masing mata bor dengan menggunakan persamaan (2). Terakhir, dengan putaran spindle yang telah diketahui penghitungan dilanjutkan dengan menghitung kebutuhan daya motor servo dari setiap mata bor dengan persamaan (3). 


\subsubsection{Penghitungan Gaya Sistem Hidrolik}

Dengan data diameter silinder dan shaft piston yang telah didapat kemudian menggunakan persamaan (4) dapat diketahui luas area kerja sistem hidrolik tersebut. Selanjutnya, mengamati pressure regulator yang terdapat pada hydraulic power unit untuk mengetahui tekanan kerja yang dihasilkan. Setelah mengetahui tekanan kerja tersebut, dengan menggunakan persamaan (5) dapat diketahui gaya yang dihasilkan oleh sistem hidrolik.

\subsubsection{Penghitungan Gaya Keluaran Motor Servo}

Diawali dengan melihat torsi yang dihasilkan motor servo berdasarkan katalog produsen setelah itu memilih pitch ballscrew yang akan digunakan. Kemudian menggunakan persamaan (6) menghitung gaya yang bisa dihasilkan oleh kombinasi motor servo dengan komponen ballscrew yang digunakan. Gaya yang dikeluarkan ini dibandingkan dengan gaya dari sistem hidrolik dan thrust axial force untuk diameter mata bor terbesar. Proses perancangan dapat diimplementasikan jika gaya yang dikeluarkan motor servo dan ballscrew sama dengan atau lebih besar dibandingkan gaya sistem hidrolik dan thrust axial force mata bor diameter terbesar. Jika gaya keluaran motor servo tersebut belum mencukupi, maka ditambahkan komponen gear ratio dengan perbandingan yang dibutuhkan untuk mencapai gaya keluaran yang diinginkan.

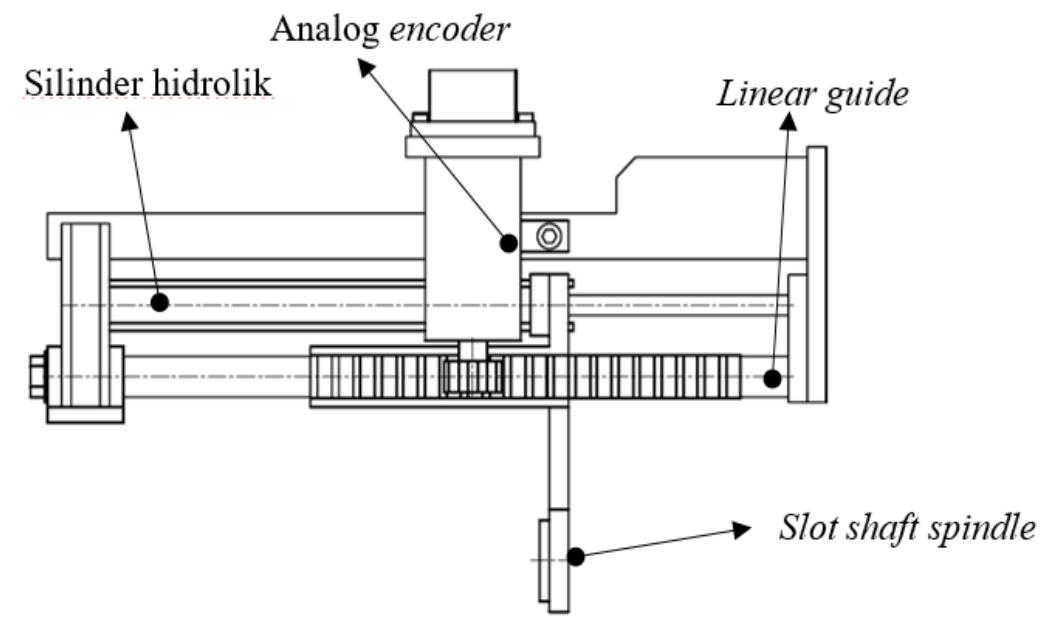

Gambar 1. Desain Drilling Axis Lama pada Mesin 


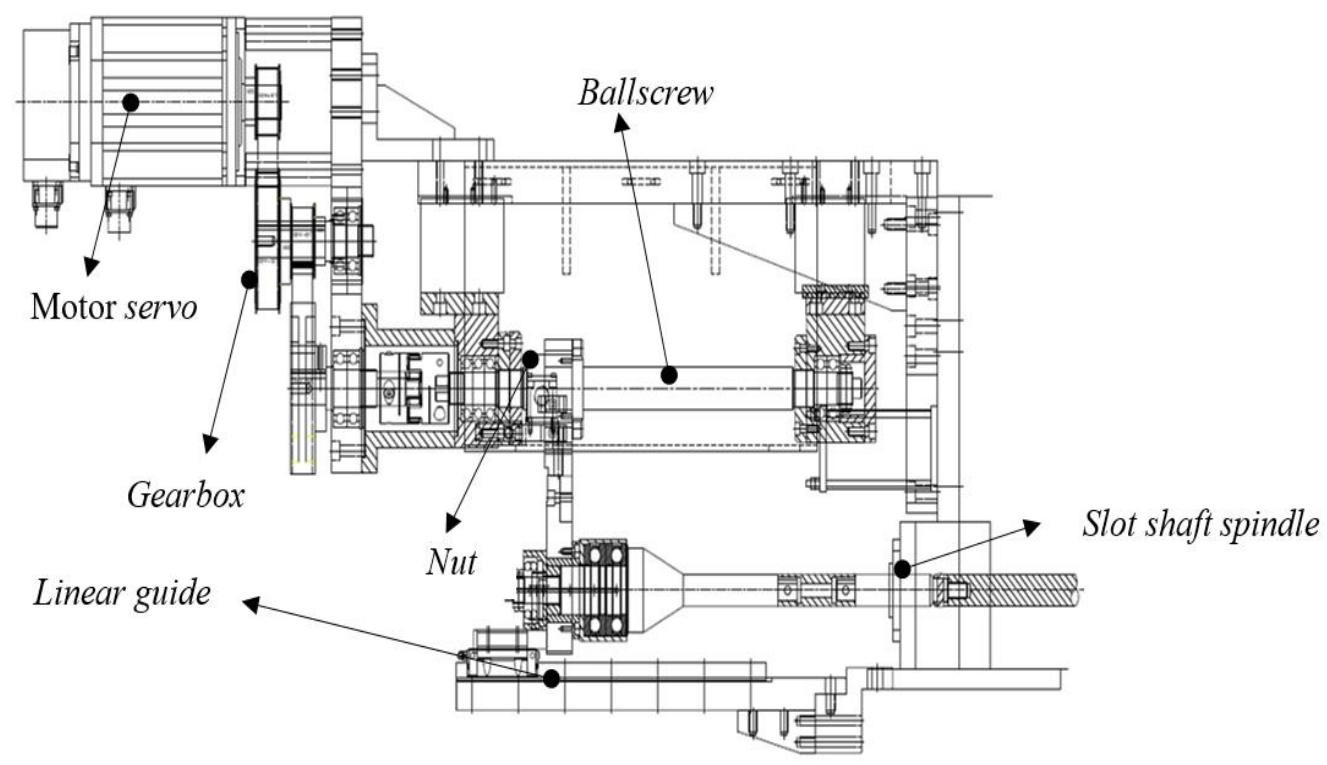

Gambar 2. Desain Rancangan Drilling Axis baru

\section{HASIL DAN PEMBAHASAN}

\subsection{Data Lapangan}

Berikut data lapangan dan juga data dari katalog komponen yang akan digunakan dalam proses desain mekanisme ballscrew

- Workpiece material : structural steel

- Cutting speed untuk material structural steel : $55 \mathrm{~m} / \mathrm{min}$

- Material factor untuk structural steel : 1,4

- Diameter shaft piston : $90 \mathrm{~mm}$

- Diameter silinder hidrolik : $125 \mathrm{~mm}$

- Tekanan sistem hidrolik minimum : $60 \mathrm{bar}=600 \mathrm{~N} / \mathrm{cm}^{2}$

- Tekanan sistem hidrolik maksimum : $85 \mathrm{bar}=850 \mathrm{~N} / \mathrm{cm}^{2}$

\subsection{Penghitungan dan Analisa Kebutuhan Daya Motor}

Dengan menggunakan persamaan (1), (2), dan (3) penghitungan kebutuhan daya motor servo

Tabel 1. Putaran spindle, thrust axial force, dan power motor servo

\begin{tabular}{ccccccc}
\hline No. & $\begin{array}{c}\text { Diameter } \\
\text { twist drill } \\
(\mathbf{m m})\end{array}$ & $\begin{array}{c}\text { Cutting } \\
\text { speed } \\
(\mathbf{M} / \mathbf{m i n})\end{array}$ & $\begin{array}{c}\text { feedrate } \\
(\mathbf{m m} / \mathbf{r e v})\end{array}$ & $\begin{array}{c}\text { Putaran } \\
\text { Spindle } \\
(\mathbf{R P M})\end{array}$ & $\begin{array}{c}\text { Thrust } \\
\text { axial } \\
\text { force }(\mathbf{N})\end{array}$ & $\begin{array}{c}\text { Power } \\
\text { Motor } \\
(\mathbf{k W})\end{array}$ \\
\hline 1 & 18 & 55 & 0.24 & 973.11 & $4,280.41$ & 2.30 \\
\hline 2 & 20 & 55 & 0.25 & 875.80 & $4,923.93$ & 2.64 \\
\hline 3 & 21 & 55 & 0.255 & 834.09 & $5,257.89$ & 2.82 \\
\hline 4 & 22 & 55 & 0.26 & 796.18 & $5,599.93$ & 3.01 \\
\hline 5 & 23 & 55 & 0.265 & 761.56 & $5,950.04$ & 3.20 \\
\hline 6 & 24 & 55 & 0.27 & 729.83 & $6,308.17$ & 3.39 \\
\hline 7 & 25 & 55 & 0.28 & 700.64 & $6,777.31$ & 3.65 \\
\hline 8 & 26 & 55 & 0.289 & 673.69 & $7,240.51$ & 3.90 \\
\hline 9 & 27 & 55 & 0.298 & 648.74 & $7,717.57$ & 4.16 \\
\hline 10 & 28 & 55 & 0.307 & 625.57 & $8,208.40$ & 4.43 \\
\hline 11 & 29 & 55 & 0.316 & 604.00 & $8,712.94$ & 4.71 \\
\hline 12 & 30 & 55 & 0.325 & 583.86 & $9,231.13$ & 5.00 \\
\hline 13 & 32 & 55 & 0.343 & 547.37 & $10,308.20$ & 5.60 \\
\hline
\end{tabular}




\begin{tabular}{ccccccc}
\hline 14 & 33 & 55 & 0.352 & 530.79 & $10,866.96$ & 5.91 \\
\hline 15 & 34 & 55 & 0.361 & 515.17 & $11,439.13$ & 6.23 \\
\hline 16 & 36 & 55 & 0.38 & 486.55 & $12,651.77$ & 6.91 \\
\hline 17 & 38 & 55 & 0.392 & 460.95 & $13,712.28$ & 7.50 \\
\hline 18 & 40 & 55 & 0.404 & 437.90 & $14,808.70$ & 8.12 \\
\hline
\end{tabular}

Dari data yang tercantum dalam tabel 1, nilai putaran spindle hasil penghitungan pada mesin hasilnya berbanding terbalik dengan diameter twist drill. Semakin kecil diameter twist drill yang digunakan maka putaran spindle yang dibutuhkan semakin besar. Putaran spindle terbesar untuk proses pengeboran adalah 973,11 rpm sedangkan putaran spindle terkecil adalah 437,90 rpm.

Hasil berbeda didapat dari penghitungan thrust axial force dan daya motor servo. Semakin besar diameter twist drill yang digunakan untuk proses pengeboran pada mesin maka thrust axial force yang dibutuhkan juga semakin besar. Artinya gaya yang dibutuhkan twist drill untuk melakukan penyayatan terhadap benda kerja semakin besar. Berdasarkan hasil perhitungan, maka thrust axial force terbesar yang dibutuhkan dalam pengoperasian mesin Ficep ini sebesar 14.808,7 $\mathrm{N}$ untuk pengeboran dengan menggunakan twist drill diameter 40 mm. Sedangkan untuk motor servo, semakin besar diameter twist drill maka daya motor servo yang dibutuhkan juga semakin besar. Dari data hasil penghitungan terkait besaran daya motor servo yang dibutuhkan, daya motor servo terbesar yang dibutuhkan sebagai penggerak adalah $8,12 \mathrm{~kW}$ sedangkan daya terkecil yang dibutuhkan $2,30 \mathrm{~kW}$. Lebih jelasnya, perbandingan data antara putaran spindle dengan daya motor servo dapat dilihat dalam gambar 3.

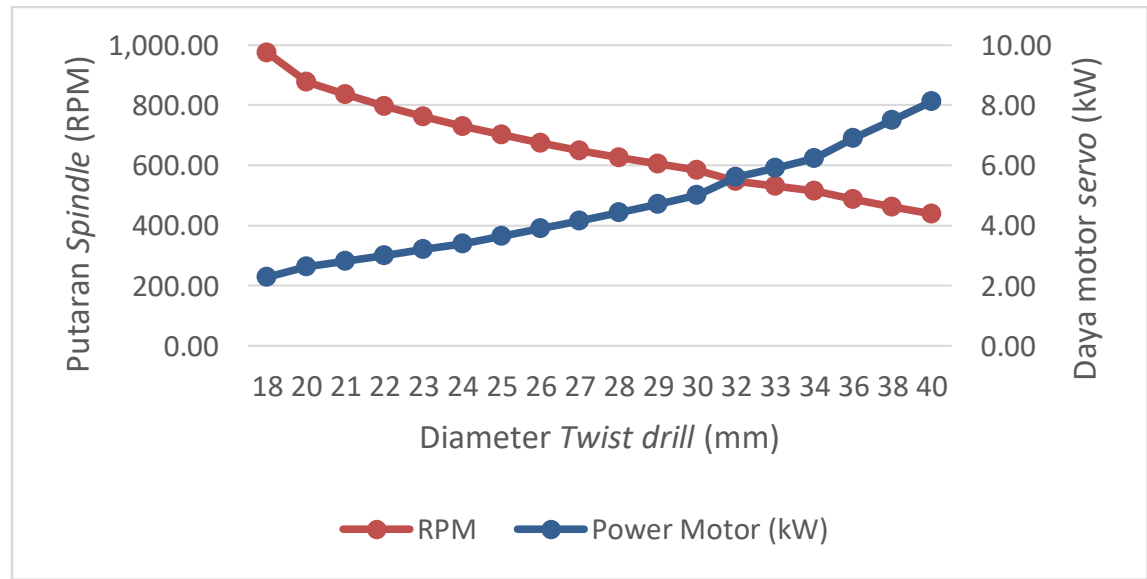

Gambar 3. Perbandingan putaran spindle dengan daya motor

\subsection{Penghitungan Sistem Hidrolik}

Dengan menggunakan persamaan (4) dan (5) penghitungan gaya yang dihasilkan oleh sistem hidrolik yang diawali dengan menghitung luas area kerja silinder hidrolik.

$$
\begin{gathered}
\text { Forward piston area }(\mathrm{A})=\frac{\pi \mathrm{x}\left(\mathrm{D}^{2}-\mathrm{d}^{2}\right)}{4} \\
\text { Forward piston area }(\mathrm{A})=\frac{3,14 \mathrm{x}\left((125 \mathrm{~mm})^{2}-(90 \mathrm{~mm})^{2}\right)}{4} \\
\text { Forward piston area }(\mathrm{A})=5.907,13 \mathrm{~mm}^{2}
\end{gathered}
$$

Selanjutnya, gaya maksimum dan gaya minimum yang dihasilkan oleh sistem hidrolik adalah

$$
P \max =\frac{F \max }{\mathrm{A}}
$$




$$
\begin{gathered}
0,85 \mathrm{kN} / \mathrm{cm}^{2}=\frac{\text { Fmax }}{59,07 \mathrm{~cm}^{2}} \\
\text { Fmax }=50,21 \mathrm{kN} \\
\text { Pmin }=\frac{\text { Fmin }}{\mathrm{A}} \\
0,6 \mathrm{kN} / \mathrm{cm}^{2}=\frac{\text { Fmax }}{59,07 \mathrm{~cm}^{2}} \\
\text { Fmin }=35,44 \mathrm{kN}
\end{gathered}
$$

Berdasarkan hasil penghitungan diatas, gaya dorong sistem hidrolik untuk proses pengeboran maksimal sebesar $50,21 \mathrm{kN}$ dan gaya dorong minimal sebesar $35,44 \mathrm{kN}$. Gaya dorong terkecil yang dihasilkan oleh sistem hidrolik dibandingkan dengan thrust axial force untuk twist drill dengan ukuran diameter terbesar bernilai lebih besar. Perbandingan ini menunjukan kemampuan gaya dorong yang dihasilkan oleh penggerak mesin gurdi harus lebih besar dibandingkan thrust axial force yang dibutuhkan untuk proses pengeboran dengan menggunakan ukuran diameter twist drill terbesar pada mesin tersebut. Jika gaya dorong yang mampu dihasilkan dari penggerak yang digunakan lebih kecil dari thrust axial force yang dibutuhkan untuk proses pengeboran, maka proses pengeboran material tidak dapat terjadi.

\subsection{Penghitungan dan Analisa Gaya Keluaran Motor Servo}

Analisa ini menggunakan daya motor servo terbesar hasil penghitungan yaitu 8,12 kW. Penentuan daya motor servo dipilih berdasarkan kebutuhan thrust axial force terbesar yang dibutuhkan dari penggerak untuk melakukan proses pengeboran material. Artinya, jika mampu menggerakan proses pengeboran material benda kerja dengan diameter twist drill terbesar yang membutuhkan thrust axial force besar maka untuk proses pengeboran material benda kerja dengan menggunakan diameter twist drill yang lebih kecil. Dengan menggunakan persamaan (6) yang telah dicantumkan sebelumnya, hasil penghitungan gaya keluaran yang dihasilkan oleh kombinasi motor servo dan ballscrew dapat dilihat pada tabel 2 berikut

Tabel 2. Torsi dan gaya keluaran motor servo

\begin{tabular}{cccccc}
\hline $\begin{array}{c}\text { Power Motor } \\
(\mathbf{k W})\end{array}$ & $\begin{array}{c}\text { Torsi } \\
(\mathbf{k N . m})\end{array}$ & $\begin{array}{c}\text { Pitch } \\
(\mathbf{m m})\end{array}$ & $\begin{array}{c}\text { Output force } \\
(\mathbf{k N})\end{array}$ & $\begin{array}{c}\text { Pitch } \\
(\mathbf{m m})\end{array}$ & $\begin{array}{c}\text { Output force } \\
(\mathbf{k N})\end{array}$ \\
\hline 8.12 & 0,028 & 5 & 35,29 & 10 & 17,65 \\
\hline
\end{tabular}

Seperti dapat dilihat pada tabel diatas bahwa hampir keseluruhan gaya keluaran yang Seperti dapat dilihat pada tabel diatas bahwa gaya keluaran yang dihasilkan oleh motor servo berdasaran hasil penghitungan matematis memiliki nilai yang lebih kecil dibandingkan dengan gaya yang dihasilkan oleh sistem hidrolik terbesar yaitu 50,21 kN. Bahkan, gaya keluaran yang dihasilkan ada yang besarnya lebih kecil dibandingkan dengan thrust axial force yang dibutuhkan tiap komponen twist drill. Dengan melihat hasil penghitungan berdasarkan tabel 2 diatas maka diperlukan adanya penambahan komponen gear ratio agar kombinasi sistem motor servo dengan ballscrew yang akan digunakan nantinya mampu menghasilkan gaya yang mampu melebihi gaya yang dihasilkan oleh sistem hidrolik.

Analisa lain dalam penghitungan gaya keluaran motor servo ini, pemilihan pitch ballscrew menghasilkan data berbanding terbalik dengan gaya keluaran yang dihasilkan motor servo. Semakin kecil pitch yang digunakan dalam penghitungan, semakin besar gaya yang mampu dihasilkan oleh motor servo dan harus ditransmisikan oleh ballscrew menjadi gerakan linear. Data tersebut berbeda dengan yang dicantumkan dalam katalog produsen 
komponen ballscrew. Komponen dynamic load yang dicantumkan dalam katalog ballscrew, ada kecenderungan bahwa semakin kecil pitch ballscrew yang digunakan maka dynamic load yang mampu ditransmisikan juga semakin kecil. Lebih jelasnya terkait analisa pemilihan pitch ballscrew dapat dilihat dalam gambar 4 berikut.

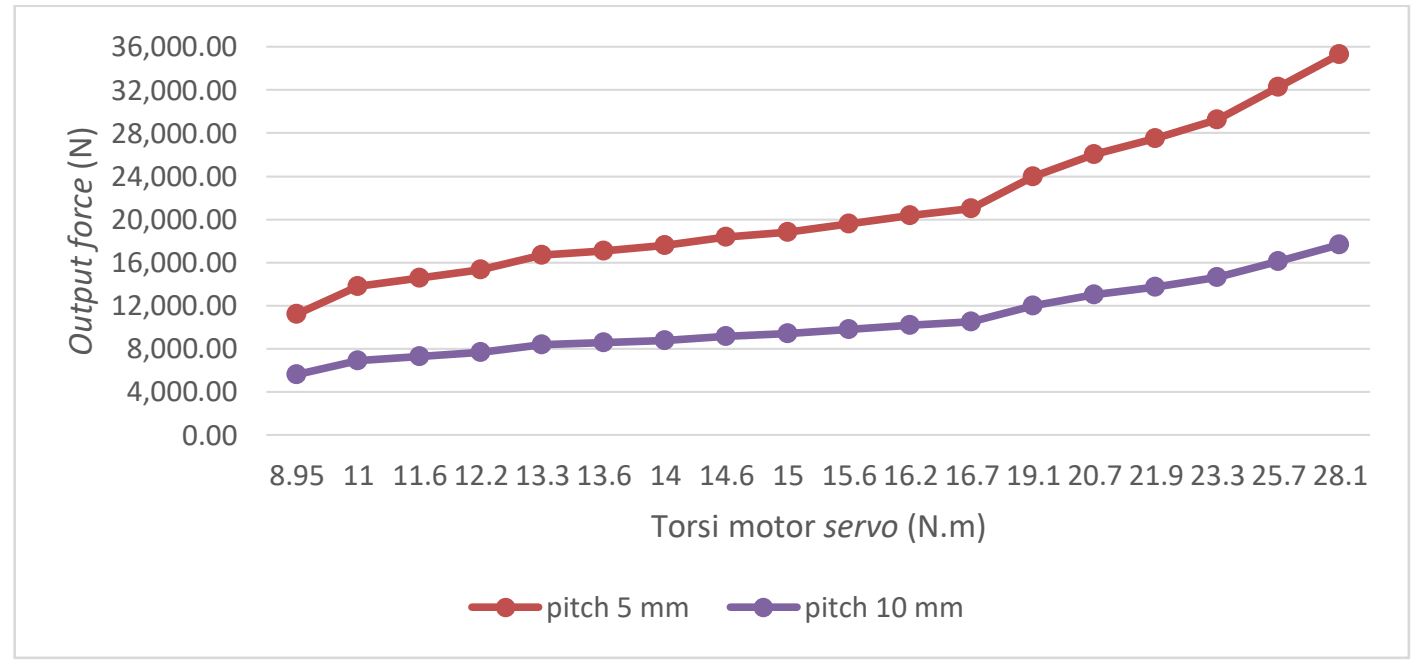

Gambar 4. Perbandingan perbedaan pemilihan pitch ballscrew

\subsection{Penambahan Gear ratio}

Karena gaya yang dihasilkan masih belum mencukupi gaya sistem hidrolik yang menjadi acuan, maka ditambahkan komponen gear ratio yang berdampak pada torsi motor servo yang dihasilkan semakin besar. Dengan persamaan (7) maka diketahui ratio gear yang dibutuhkan untuk ditambahkan pada motor servo adalah $3: 1$. Untuk melihat pengaruh penambahan gear ratio tersebut, dapat dilihat dalam tabel 3

Tabel 3. Torsi dan gaya keluaran motor servo dengan penambahan gear ratio

\begin{tabular}{ccccc}
\hline $\begin{array}{c}\text { Power Motor } \\
(\mathbf{k W})\end{array}$ & $\begin{array}{c}\text { Torsi } \\
(\mathbf{k N . m})\end{array}$ & $\begin{array}{c}\text { Pitch } \\
(\mathbf{m m})\end{array}$ & $\begin{array}{c}\text { Output force } \\
(\mathbf{k N})\end{array}$ & $\begin{array}{c}\text { Hydraulic Force } \\
(\mathbf{k N})\end{array}$ \\
\hline 8.12 & 0,084 & 10 & 52,94 & 50,21 \\
\hline
\end{tabular}

Penambahan gear ratio yang berpengaruh terhadap besaran torsi yang dihasilkan motor servo membuat perubahan terhadap gaya keluaran yang dihasilkan oleh kombinasi motor servo dan ballscrew. Karena torsi yang lebih besar meskipun dengan daya motor yang digunakan tetap, menghasilkan gaya keluaran yang nilainya lebih besar dibandingkan tanpa penggunaan komponen gear ratio dalam perancangan.

\subsection{Penentuan Komponen}

Berdasarkan hasil penghitungan diatas, selain daya motor servo yang dibutuhkan adalah daya motor terbesar hasil penghitungan yaitu $8,12 \mathrm{~kW}$. Penentuan komponen ballscrew yang akan digunakan berdasarkan penghitungan dengan tambahan gear ratio $3: 1$, maka ballscrew yang akan dipilih adalah ballscrew yang memiliki kemampuan transmisi dynamic load sebesar 52,94 $\mathrm{kN}$ dengan pitch ballscrew $10 \mathrm{~mm}$ karena nilai dynamic load tersebut sudah aman dan bisa digunakan untuk melakukan proses pengeboran benda kerja. Komponen dynamic load tersebut juga sejalan dengan penggunaan daya motor $8,12 \mathrm{~kW}$ yang disarankan dalam desain mekanisme ballscrew ini karena gaya keluaran dari motor servo yang mampu melebihi gaya sistem hidrolik dengan penambahan gear ratio $3: 1$ hanya motor servo dengan daya tersebut. 


\section{SIMPULAN}

Dari proses analisis dan penghitungan yang telah dilakukan, dapat diketahui beberapa pertimbangan dalam membuat desain mekanisme ballscrew untuk mesin gurdi diantaranya semakin besar diameter twist drill yang digunakan, daya motor servo yang digunakan sebagai penggerak drilling axis juga semakin besar, selain itu gaya dorong yang dihasilkan oleh penggerak dalam drilling axis harus lebih besar dibandingkan thrust axial force yang dibutuhkan twist drill agar proses kerja permesinan dapat terlaksana.

Dalam pemilihan komponen, penetuan pitch ballscrew secara matematis semakin kecil pitch yang digunakan dalam penghitungan, dynamic load yang harus ditransmisikan semakin besar. Sedangkan berdasarkan data yang didapat dari katalog produsen ballscrew menunjukkan nilai sebaliknya, dynamic load ballscrew dengan pitch semakin kecil maka dynamic load yang mampu ditransmisikan juga lebih kecil.

Desain mekanisme ballscrew untuk drilling axis mesin Ficep H-Beam Drilling LFB-20049 ini menyarankan penggunaan motor servo heavy duty dengan daya $8,12 \mathrm{~kW}$ ditambah gear ratio dengan perbandingan $3: 1$ didukung komponen mekanik ballscrew yang digunakan adalah DIN rolled ballscrew pitch $10 \mathrm{~mm}$ dengan ketahanan dynamic load 52,94 $\mathrm{kN}$ berdasarkan penghitungan dan analisa matematis.

\section{DAFTAR PUSTAKA}

[1] H. J. Lesmana, “ANALISIS OPTIMASI PARAMETER PERMESINAN TERHADAP WAKTU PROSES PADA PEMROGRAMAN CNC MILLING DENGAN MENGGUNAKAN MASTERCAM X5 DI PT. SERVITAMA TEKNINDO,” Bachelor Thesis, Universitas Kristen Indonesia, Jakarta, 2019.

[2] M. P. Gridharan, T. Kumar, P. Kumar, N. K. Singh, and A. G. Kumar, "Design of Ball Screw Mechanism for Retro Fit of External Grinding Machine," IOSR J. Mech. Civ. Eng., vol. 6, no. 2013, pp. 15-23, May 2013.

[3] N. Ngarifin and Y. Kusuma, "Perancangan Ulang Sistem Hidrolik pada Mesin FFAF dengan Menggunakan Manifold sebagai Pengganti Pipa," Sinergi, vol. 18, no. 3, pp. 123-126, 2014.

[4] S. Ramesh, S. D. Ashok, N. K. Naulakha, C. R. Adithyakumar, M. L. K. Reddy, and S. K. Reddy, "Energy Efficient Hydraulic Clamping System using Variable Frequency Drive in a CNC Machine," in IOP Conference Series: Materials Science and Engineering, 2018, vol. 376, no. 1, p. 012124.

[5] S. Ramesh, S. D. Ashok, and S. Nagaraj, "An Energy Conservation Strategy using variable frequency drive for a Hydraulic clamping system in a CNC Machine," Mater. Today Proc., vol. 5, no. 5, pp. 13504-13513, 2018.

[6] P. N. Parmar, V. R. Gondalia, and N. C. Mehta, "Review on advance automation of conventional lathe machine," Int J Eng Dev Res, vol. 2, no. 2, pp. 2452-2456, 2014.

[7] S. Harbintoro, "PENELITIAN EFISIENSI ENERGI PADA MESIN HORIZONTAL BORING \& MILLING,” Met. Indones., vol. 36, no. 2, pp. 76-83, 2018.

[8] Dormer Technical Handbook. Dormer Pramet.

[9] M. Subhan and A. Satmoko, "Penentuan Dimensi Dan Spesifikasi Silinder Pneumatik Untuk Pergerakan Tote Iradiator Gamma Multiguna Batan,” J. Perangkat Nukl., vol. 10, no. 2, 2017.

[10] H. Damayanti, Sutikno, and Masturi, "PEMBELAJARAN HUKUM PASCAL MENGGUNAKAN MINIATUR MESIN HIDROLIK UNTUK MENINGKATKAN KEMAMPUAN BERPIKIR KRITIS SISWA," in Prosiding Seminar Nasional Fisika (E-Journal) SNF2015, Oct. 2015, vol. 4, pp. 5-10.

[11] D. Haryanto, S. Sagino, and R. Djambiar, "REVITALISASI MESIN BUBUT," SIGMA Epsil.-Bul. Ilm. Teknol. Keselam. Reakt. Nukl., vol. 15, no. 3, 2011. 